\title{
Fate of Trace Metals in Ferrous Smectites Following Iron Oxidation
}

\author{
ROBERT J KUPPER II ${ }^{1}$, NANQING ZHOU ${ }^{2}$, CLARA S \\ CHAN $^{2}$ AND JEFFREY G CATALANO ${ }^{1}$
}

\author{
${ }^{1}$ Washington University in St. Louis \\ ${ }^{2}$ University of Delaware \\ Presenting Author: rkupper@wustl.edu
}

Iron-bearing smectites are a major alteration product of mafic rocks. Under anoxic conditions they predominantly occur as trioctahedral $\mathrm{Fe}(\mathrm{II})-\mathrm{Mg}$ phases. These clay minerals are common in the unoxygenated subsurface of modern oceanic crust and are predicted as a detrital mineral on the early Earth. Smectites incorporate various trace metals during formation but it is unclear whether subsequent iron oxidation may redistribute these elements in the structure or to aqueous solution and, if redoxactive, alter their oxidation state. Trace metals in smectites may provide potential signatures of past oxidation in the rock record, possibly dependent on the oxidation pathway.

We examined the fate of several common trace metals during smectite oxidation. Trioctahedral $\mathrm{Fe}(\mathrm{II})-\mathrm{Mg}$ smectites containing $\mathrm{V}(\mathrm{III}), \mathrm{Mn}(\mathrm{II}), \mathrm{Co}(\mathrm{II}), \mathrm{Ni}(\mathrm{II})$, or $\mathrm{Zn}(\mathrm{II})$ were synthesized using an established sol-gel procedure. Their compositions were determined by digestion followed by inductively coupled plasma optical emission spectroscopy (ICP-OES) analysis. These five clays were then oxidized by water equilibrated with $2 \% \mathrm{O}_{2}(\mathrm{~g})$ or with hydrogen peroxide. Trace element release to solution was monitored using ICP-OES and the speciation of the trace metals before and after oxidation was determined using X-ray absorption spectroscopy.

Extended X-ray absorption fine structure (EXAFS) spectra confirmed each trace metal was initially incorporated into the octahedral sheet of the smectite. Exposure to hydrogen peroxide caused greater oxidation of manganese and vanadium than exposure to dissolved $\mathrm{O}_{2}$. Peroxide also caused minor cobalt oxidation. Only vanadium displayed measurable release to solution, most likely due to the incompatibility of $\mathrm{V}(\mathrm{V})$ with the smectite structure and this species' high solubility at circumneutral $\mathrm{pH}$. Nickel and zinc EXAFS spectra showed fewer neighboring octahedral cations after smectite oxidation, implying ejection of either a portion of these metals or neighboring iron from the octahedral sheet. This effect was greater in samples exposed to hydrogen peroxide, which caused more rapid and complete iron oxidation. The loss of trace metals and the extent of vanadium, manganese and cobalt oxidation may persist in the rock record as indicators of past redox events. In particular, microbial oxidation of phyllosilicates may progress from edge sites, creating highly oxidized domains that potentially exhibit unique trace metal signatures. 